Wohnungsmarkt

\section{Ein politisches Signal}

Durch den geplanten Zusammenschluss von Vonovia und Deutsche Wohnen entsteht der größte Immobilienkonzern Europas mit 550.000 Wohnungen. Dabei dürfte es vor allem um politisches Gewicht gehen: Je größer der Konzern, desto besser lassen sich politische Risiken streuen. Schon heute ist Vonovia eine der größten Immobilienaktiengesellschaften. Schließt sich der Konzern mit der Deutsche Wohnen zusammen, würde ein Unternehmen mit einer Marktkapitalisierung von mehr als $45 \mathrm{Mrd}$. Euro entstehen. Größe ist im Wohnungsmarkt wichtig: Je gröBer ein Unternehmen, desto mehr Vorteile lassen sich im Einkauf erzielen, außerdem können bei der Bewirtschaftung Skaleneffekte erzielt werden.

Dies dürfte jedoch nicht der entscheidende Grund sein. Schließlich haben beide Unternehmen schon zweimal versucht zu fusionieren. Letztlich waren es aber gerade die Investierenden, die eine Fusion ablehnten, da die ökonomischen Vorteile als nicht gewichtig genug wahrgenommen wurden. Beide Unternehmen sind bereits sehr groß und können am Kapitalmarkt günstige Finanzierungskonditionen erhalten. Die Portfolien der beiden Unternehmen haben unterschiedliche regionale Schwerpunkte, weshalb Einsparungen in der Bewirtschaftung limitiert sein dürften. In der Vergangenheit war es den Investierenden darüber hinaus wichtig, mehrere Unternehmen zu haben, die konkurrieren und unterschiedliche regionale Strategien verfolgen. Somit können Anlagerisiken besser diversifiziert werden. Vor diesem Hintergrund dürfte auch Marktmacht nicht entscheidend sein. Letztlich ist für die Erzielung von Preissetzungsmacht der Wohnungsmarkt insgesamt zu kleinteilig. In früheren Verfahren stellte das Kartellamt zwar fest, dass einzelne Unternehmen in Städten des Ruhrgebiets auf einen Marktanteil von $20 \%$ kommen, doch damit ist noch keine ausreichende Marktmacht verbunden. Schließlich stehen den Kunden weiterhin zahlreiche Alternativen offen, sowohl in der Stadt als auch außerhalb. In Berlin, wo die beiden Unternehmen künftig über 150.000 Wohnungen bewirtschaften, liegt der Marktanteil bei Mietwohnungen bei unter $9 \%$.

Ausschlaggebend für die Fusion dürfte vielmehr die Politik sein: Durch politische Interventionen entstehen Risiken für die Unternehmen, die tendenziell für große Marktteil-

(C) Der/die Autor:in(nen) 2021. Open Access: Dieser Artikel wird unter der Creative Commons Namensnennung 4.0 International Lizenz veröffentlicht (creativecommons.org/licenses/by/4.0/deed.de).

Open Access wird durch die ZBW - Leibniz-Informationszentrum Wirtschaft gefördert. nehmende besser zu bewältigen sind als für kleine Unternehmen oder Privateigentümer:innen. Dabei haben die Unwägbarkeiten in den vergangenen Jahren noch zugenommen: Sie reichen von Enteignungen über weitreichende Mietenstopps bis zu Einschränkungen bei der Umlagefähigkeit nach Modernisierungen. Auch in anderen Branchen wie etwa dem Bankensektor sind Regulierungen ein wichtiger Treiber von Zusammenschlüssen. Ganz konkret etwa könnte eine vergrößerte Vonovia robuster gegenüber einer Enteignung aufgestellt sein. Niemand kann sich vorstellen, dass eine Enteignung, wie sie die Initiative „Deutsche Wohnen \& Co. enteignen“ fordert, wirklich erfolgt und die Unternehmen deutlich unter dem Marktwert entschädigt werden. Dennoch könnte eine entsprechende politische Initiative für sehr viel Unruhe sorgen, die von einem Unternehmen, das außerhalb Berlins stabile Erträge erwirtschaftet, besser verkraftet werden könnte. Auch bei künftigen Mietpreisregulierungen, die lokal sehr unterschiedlich wirken, kann Größe helfen, da zumindest einige Märkte - wie etwa im Ruhrgebiet - kaum betroffen sein werden.

Nicht zuletzt gewinnt das Unternehmen durch Größe auch Mitsprachemöglichkeiten. Ein Unternehmen mit mehr als einer halben Million Wohnungen kann kaum übergangen werden, und so wird das Unternehmen bei Anhörungen, aber auch bei politischen Hintergrundgesprächen oder Diskussionen präsenter sein. Dies ist allerdings Chance und Risiko zugleich: Vonovia könnte als konstruktiver Gesprächspartner Reputation gewinnen und seine eigenen Anliegen besser vertreten, aber das Unternehmen könnte sich auch endgültig als Zielscheibe für politische Initiativen und Mieterwut etablieren. Die geplante Fusion stellt vor diesem Hintergrund eher eine unbeabsichtigte Folge der zahlreichen Interventionen in den Wohnungsmarkt dar. Und es ist zu erwarten, dass noch mehr Unternehmen sich zusammenschließen werden, um robuster gegenüber Mietpreisregulierungen und anderen Eingriffen zu werden. Gerade Kleinvermietende könnten so zunehmend aus dem Markt gedrängt werden, da sie in der Regel die größten Probleme haben, sich auf Änderungen im Regulierungsrahmen einzustellen. Bereits mit der Einführung des Genehmigungsvorbehalts bei Aufteilungen und Umwandlungen wurde der Markt für viele Kleinvermietende limitiert. Auch wenn Marktmacht im Wohnungsmarkt keine große Rolle spielt, ist diese Entwicklung kritisch zu beobachten. Schließlich sichert ein kleinteiliger Mietwohnungsmarkt ein vielfältiges Angebot - gerade darin hat sich der deutsche Mietwohnungsmarkt immer von anderen Märkten unterschieden.

Michael Voigtländer Institut der deutschen Wirtschaft voigtlaender@iwkoeln.de 